\title{
Training infection control and hospital hygiene professionals in Europe, 2010: agreed core competencies among 33 European countries
}

S Brusaferro ${ }^{1}$, B Cookson ${ }^{2}$, S Kalenic ${ }^{3}$, T Cooper $^{4}$, J Fabry ${ }^{5}$, R Gallagher ${ }^{6}$, P Hartemann ${ }^{7}$, K Mannerquist ${ }^{8}$, W Popp ${ }^{9}$, G Privitera $^{10}$, C Ruef ${ }^{11}$, P Viale ${ }^{12}$, F Coiz $^{1}$, E Fabbro (elisa.fabbro@uniud.it) ${ }^{1}$, C Suetens ${ }^{13}$, C Varela Santos ${ }^{14}$, National representatives of the Training in Infection Control in Europe (TRICE) project ${ }^{15}$

1. Department of Medical and Biological Sciences, University of Udine, Udine, Italy

2. Division of Infection and Immunity, University College London, London, United Kingdom

3. Department of Medical Microbiology, University of Zagreb, Zagreb, Croatia

4. Infection Prevention Society, London, United Kingdom

5. University Claude Bernard, Lyon, France

6. Nurse Advisor Infection Prevention and Control, Royal College of Nursing, London, United Kingdom

7. Hospital Hygiene Service, Chu De Nancy and Desp Seres Faculty of Medicine, Vandoeuvre-Nancy, France

8. Swedish Institute for Infectious Disease Control, Stockholm, Sweden

9. Hospital Hygiene, University Clinics Essen, Essen, Germany

10. Department of Translational Research and New Technology in Medicine and Surgery, University of Pisa, Pisa, Italy

11. ESCMID representative-Division of Infectious Diseases and Hospital Epidemiology, Hirslanden Hospital and Medical Center, Zurich, Switzerland

12. Infectious Disease Unit, Teaching Hospital S. Orsola-Malpighi, Alma Mater Studiorum University of Bologna

13. Surveillance and Response Support Unit, European Centre for Disease Prevention and Control, Stockholm, Sweden

14. Public Health Training section, European Centre for Disease Prevention and Control, Stockholm, Sweden

15. The members of the project are listed at the end of the article

Citation style for this article:

Brusaferro S, Cookson B, Kalenic S, Cooper T, Fabry J, Gallagher R, Hartemann P, Mannerquist K, Popp W, Privitera G, Ruef C, Viale P, Coiz F, Fabbro E, Suetens C, Varela Santos C, National representatives of the Training in Infection Control in Europe (TRICE) project. Training infection control and hospital hygiene professionals in Europe, 2010: agreed core competencies among 33 European countries. Euro Surveill. 2014;19(49):pii=20985. Available online: http://www. eurosurveillance.org/ViewArticle.aspx?Articleld=20985

The harmonisation of training programmes for infection control and hospital hygiene $(\mathrm{IC} / \mathrm{HH})$ professionals in Europe is a requirement of the Council recommendation on patient safety. The European Centre for Disease Prevention and Control commissioned the 'Training Infection Control in Europe' project to develop a consensus on core competencies for IC/HH professionals in the European Union (EU). Core competencies were drafted on the basis of the Improving Patient Safety in Europe (IPSE) project's core curriculum (CC), evaluated by questionnaire and approved by National Representatives (NRs) for IC/HH training. NRs also re-assessed the status of $\mathrm{IC} / \mathrm{HH}$ training in European countries in 2010 in comparison with the situation before the IPSE CC in 2006. The IPSE CC had been used to develop or update 28 of $51 \mathrm{IC} / \mathrm{HH}$ courses. Only 10 of 33 countries offered training and qualification for IC/ $\mathrm{HH}$ doctors and nurses. The proposed core competencies are structured in four areas and 16 professional tasks at junior and senior level. They form a reference for standardisation of IC/HH professional competencies and support recognition of training initiatives.

\section{Introduction}

There has been an increase in prevention and control activities in the field of infection control and hospital hygiene $(\mathrm{IC} / \mathrm{HH})$ in recent years owing to an increased awareness of patient safety and the considerable burden of healthcare-associated infections (HAls) [1]. While this strengthens the role of $\mathrm{IC} / \mathrm{HH}$ professionals [2], the process has not always been accompanied by a commensurate increase in the resources for $\mathrm{IC} / \mathrm{HH}$ prevention and control [3]. Many reports have documented a shortage of qualified IC/HH doctors and IC/HH nurses [4-7], and there are large differences among European countries in the qualifications required to work as an $\mathrm{IC} / \mathrm{HH}$ professional [8]. The need to guarantee healthcare quality standards throughout Europe, including for $\mathrm{IC} / \mathrm{HH}$, has been further stressed by the approval of the European Union (EU) directive on cross-border patient mobility [9]. In addition, topics such as patient safety, quality improvement, continuing professional development and risk management have become increasingly important and should be part of the content of contemporary IC/HH training programmes [2,10-12].

In 2006, a European survey organised by the Improving Patient Safety in Europe (IPSE) project [8] indicated a lack of national $\mathrm{IC} / \mathrm{HH}$ training programmes and of professional profiles for $\mathrm{IC} / \mathrm{HH}$ practitioners in many European countries. Experts from the IPSE project and representatives of the European Society of Clinical Microbiology and Infectious Diseases (ESCMID) subsequently developed a European core curriculum for training of IC/HH professionals across Europe [8]. 
In July 2008 , at the end of the IPSE project, its activities were transferred to the European Centre for Disease Prevention and Control (ECDC) in Stockholm. In 2009, considering the importance of continued support to national $\mathrm{IC} / \mathrm{HH}$ training programmes and the opportunity to build further on the outputs of IPSE, ECDC issued an open call for tender (i) to evaluate the use of the European core curriculum developed by IPSE in European countries and reassess the needs for $\mathrm{IC} / \mathrm{HH}$ training in these countries, (ii) to set up a network for $\mathrm{IC} / \mathrm{HH}$ training, and (iii) to propose a strategy for further support to $\mathrm{IC} / \mathrm{HH}$ training in EU/EEA Member States (publication reference OJ/2009/06/16-PROC/2009/027).

The contract was awarded to the Training in Infection Control in Europe (TRICE) project under the coordination of the University of Udine, Italy. The TRICE project explored the state of the art of training $\mathrm{IC} / \mathrm{HH}$ professionals in Europe, evaluated the European core curriculum together with experts from participating countries, and proposed an agreed list of core competencies to guide the standardisation of training of European IC/ HH professionals [13].

The aim of this paper is to report the evolution of the status of European $\mathrm{IC} / \mathrm{HH}$ activities and practitioners between 2006 and 2010 and the finalisation of the agreed European IC/HH core competencies.

\section{Methods}

The TRICE project was carried out between January and September 2010 and had two stages: a questionnairebased survey, followed by a face-to-face consultation. Member States of the EU, the European Economic Area (EEA) and EU candidate countries were invited by ECDC to participate and were asked to designate a national representative (NR) specifically for the project.

The NR who responded to the questionnaire were nominated by the governments of each country. They were either doctors or nurses and chosen according to a profile defined by ECDC, as part of the project. In this profile it was clearly explained that the NRs had to contribute to the survey reporting the national state of the art on the topic and that they were to interact with all relevant infection control leads and other appropriate professionals in their country.

The 30 countries (33 respondents) included all EU Member States (Austria, Belgium, Bulgaria, Croatia (at the time a candidate country), Cyprus, Czech Republic, Denmark, Estonia, Finland, France, Germany, Greece, Hungary, Ireland, Italy, Latvia, Lithuania, Luxembourg, Malta, the Netherlands, Poland, Portugal, Romania, Slovakia, Slovenia, Spain, Sweden, the United Kingdom (UK) (England, Northern Ireland, Scotland and Wales provided separate answers), one EEA country (Norway) and one EU candidate countries (Turkey). The IPSE 2006 survey lacked the participation of Cyprus, Greece, and Romania.
NRs had to be national experts on IC/HH, as they were required to document their national situations, collect data, complete questionnaires, and comment upon and approve TRICE documents. However, only nine of the 33 respondents were the same person as the one who had completed the IPSE 2006 questionnaire. For this reason, NRs were asked to validate data with other professionals in their country before returning the completed TRICE questionnaire. To facilitate this process, answers to the 2006 IPSE questionnaire were sent to the NRs together with the TRICE questionnaire. NRs were asked to contact, in case of need, IC/HH training coordinators in their country to ensure that replies were representative for the country.

\section{Development of the core competencies for $\mathrm{IC} / \mathrm{HH}$ professionals in the EU comprised the following activities:}

- Re-assessment by questionnaire of the existence of national programmes and courses for $\mathrm{IC} / \mathrm{HH}$ training and of the current status and profile of $\mathrm{IC} / \mathrm{HH}$ professionals. Countries were asked, where possible, to compare their situation in 2010 with that in 2006 (as evaluated by the IPSE project);

- Submission to the NRs of the European core curriculum for training of $\mathrm{IC} / \mathrm{HH}$ practitioners developed by IPSE, together with a proposal for stratifying the core competencies in the curriculum into different levels of expertise (essential, intermediate and advanced level);

- Discussion through working groups and final general consensus of results and views at a meeting of NRs on 21 to 22 June 2010 in Udine (Italy); validation and approval by all the NRs and meeting participants of a draft of these results and views;

- Development of a final document on these core competencies, approved by the NRs.

As European countries have several different definitions, interpretations and reference frameworks relevant to competencies, the term 'competency', agreed by NRs, was defined as: 'the proven ability to use knowledge, skills and personal, social and/or methodological abilities, in work or study situations and in professional and personal development' [14].

The questionnaire was based on the previous IPSE project. It included instructions on how to fill in the responses, definitions of terms and relevant references to the IPSE project. Possible misinterpretations of the questions were addressed during data validation at a meeting of the NRs in June 2010. A pilot study was performed before launching the questionnaire. All data were individually validated by NRs twice before finalising the analysis, first to confirm that the questionnaire had been filled in and the answers had been discussed at the workshop meeting and again for the draft of the final report including tables and figures. 
Presence of a national curriculum or programme for training of infection control and hospital hygiene doctors and nurses in European countries, 2006 (IPSE; 31 countries) and 2010 (TRICE; 33 countries)
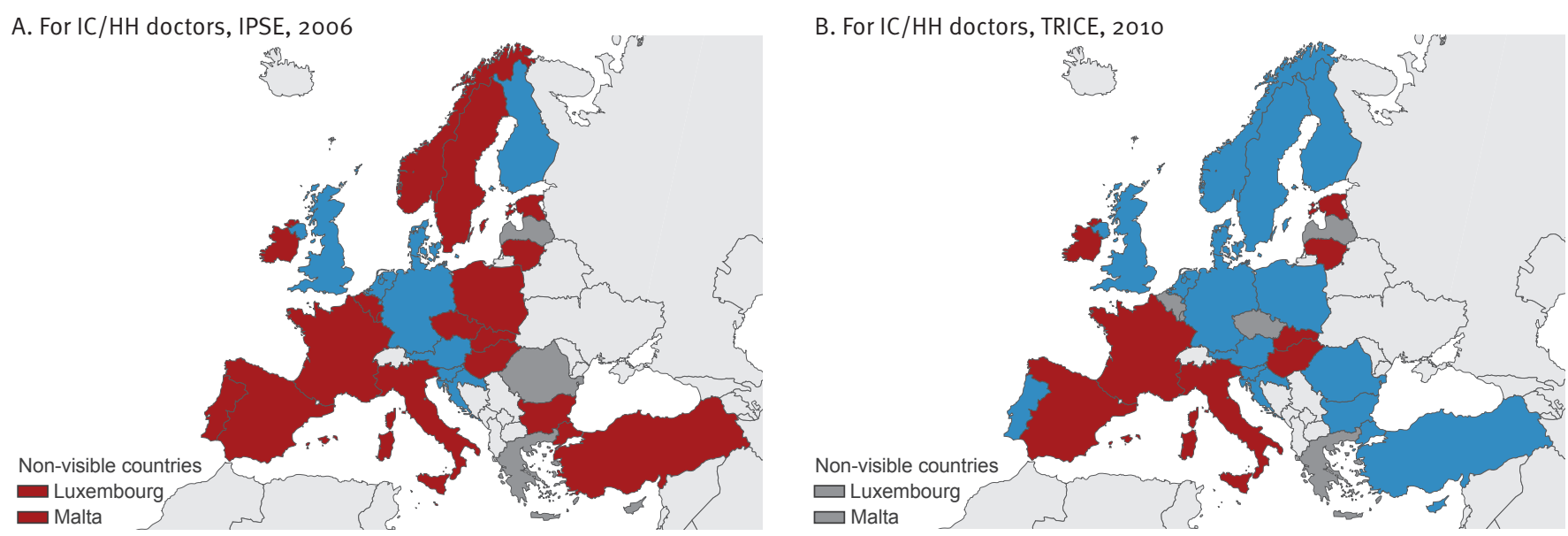

C. For IC/HH nurses, IPSE, 2006

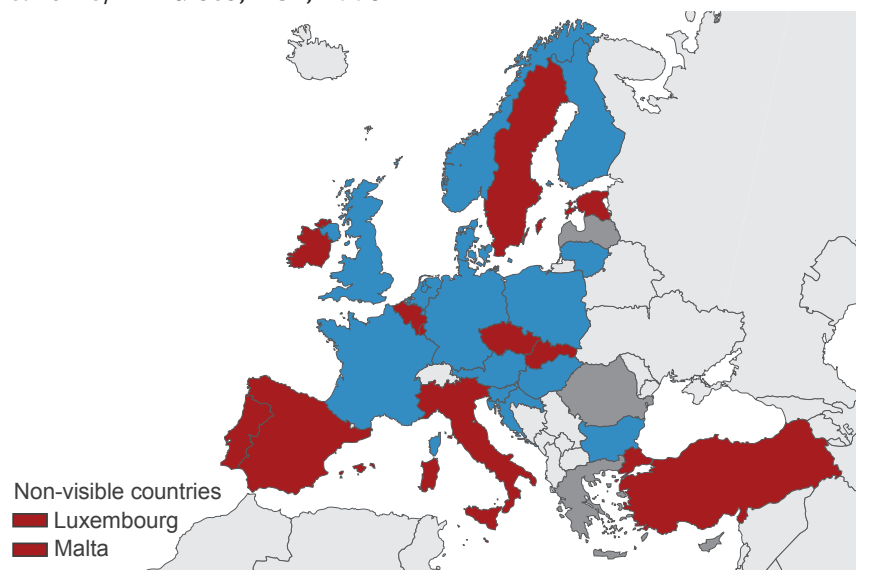

D. For IC/HH nurses, TRICE, 2010

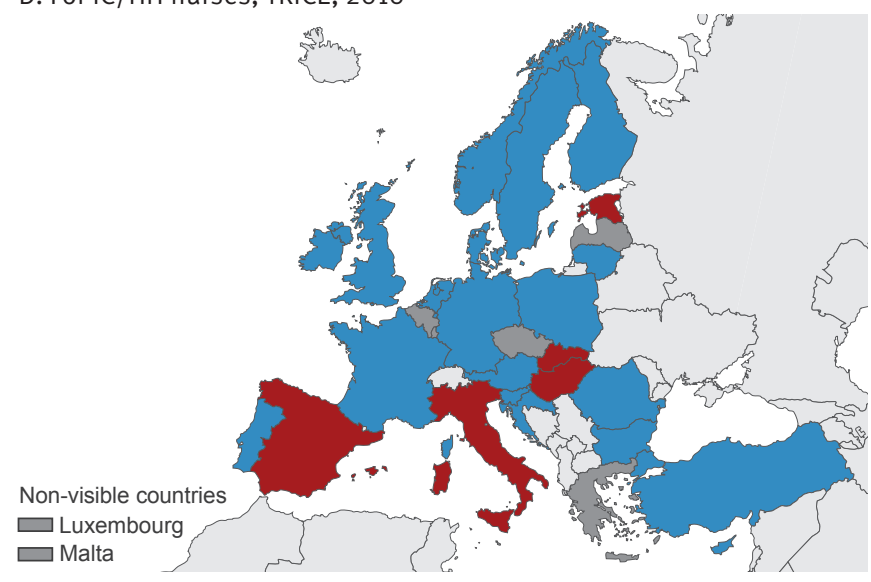

$\square$ Yes (at national or professional level)

$\square$ Not answered

$\square$ Not included in the survey
B. For IC/HH doctors, TRICE, 2010

$\square$ Luxembourg $\square$ Malta

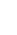




\section{TABLE 1}

Type of degree or learning leading to infection control/hospital hygiene qualification for doctors and for nurses in European countries, 2006 (IPSE; 31 countries) and 2010 (TRICE; 33 countries)

\begin{tabular}{|l|c|c|c|c|}
\hline \multirow{2}{*}{$\begin{array}{l}\text { Type of degree or learning leading } \\
\text { to IC/HH qualification }\end{array}$} & \multicolumn{3}{|c|}{ Number (percentage) of countries with characteristics for } \\
\cline { 2 - 5 } & $2006(\mathrm{n}=31)$ & $2010(\mathrm{n}=33)$ & $2006(\mathrm{n}=31)$ & $2010(\mathrm{n}=33)$ \\
\cline { 2 - 5 } & $4(13 \%)$ & $4(12 \%)$ & $10(32 \%)$ & $10(30 \%)$ \\
\hline IC/HH specialty & $2(6 \%)$ & $5(15 \%)$ & $1(3 \%)$ & $0(0 \%)$ \\
\hline IC/HH sub-specialty & $3(10 \%)$ & $5(15 \%)$ & $3(10 \%)$ & $4(12 \%)$ \\
\hline Continuous training (government) & $12(39 \%)$ & $10(30 \%)$ & $11(35 \%)$ & $11(33 \%)$ \\
\hline Continuous training (professional bodies) & $3(10 \%)$ & $3(9 \%)$ & $3(10 \%)$ & $3(9 \%)$ \\
\hline Board certification & $6(19 \%)$ & $9(27 \%)$ & $5(16 \%)$ & $8(24 \%)$ \\
\hline University degree & NA & $1(3 \%)$ & NA & $1(3 \%)$ \\
\hline Other & $12(39 \%)$ & $10(30 \%)$ & $8(26 \%)$ & $8(24 \%)$ \\
\hline Question not answered & & & \\
\hline
\end{tabular}

IC/HH: infection control and hospital hygiene; IPSE: Improving Patient Safety in Europe; NA: not available; TRICE: Training needs assessment in Infection Control in Europe.

a More than one answer allowed.

\section{FIGURE 2}

Existing infection control and hospital hygiene training courses based on the European core curriculum developed by IPSE in 2006, as assessed by TRICE survey in 2010

Yes or partially

No

$\square$ Future plans to consider the European core curriculum developed by IPSE

$\square$ Not answered

$\square$ Not included in the survey

\author{
moner
}

Non-visible countries

$\square$ Luxembourg

Malta

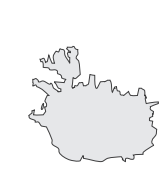

IC/HH: infection control and hospital hygiene; IPSE: Improving Patient Safety in Europe; TRICE: Training needs assessment in Infection Control in Europe. 
Characteristics of the professional status (job description, professional profile and official recognition) of infection control/ hospital hygiene doctors and nurses in European countries, 2006 (IPSE; 31 countries) and 2010 (TRICE; 33 countries)

\begin{tabular}{|c|c|c|c|c|}
\hline \multirow{3}{*}{ Characteristics of professional status } & \multicolumn{4}{|c|}{ Number (percentage) of countries with characteristics for } \\
\hline & \multicolumn{2}{|c|}{$\mathrm{IC} / \mathrm{HH}$ doctors } & \multicolumn{2}{|c|}{$\mathrm{IC} / \mathrm{HH}$ nurses } \\
\hline & $2006(n=31)$ & $2010(n=33)$ & $2006(n=31)$ & $2010(n=33)$ \\
\hline Presence of job description & $11(36 \%)$ & $17(52 \%)$ & $19(61 \%)$ & $23(70 \%)$ \\
\hline Presence of a professional profile definition & $18(58 \%)$ & $28(85 \%)$ & $22(71 \%)$ & $27(82 \%)$ \\
\hline $\begin{array}{l}\text { Presence of official recognition by the degree of } \\
\text { IC/HH for doctors and nurses (any) }\end{array}$ & $13(42 \%)$ & 16 (49\%) & $20(65 \%)$ & 19 (58\%) \\
\hline Official recognition by health care authorities & $10(32 \%)$ & $11(33 \%)$ & $18(58 \%)$ & $14(42 \%)$ \\
\hline Official recognition by universities & $2(7 \%)$ & $4(12 \%)$ & $3(10 \%)$ & $5(15 \%)$ \\
\hline Official recognition by professional bodies & $4(13 \%)$ & $8(24 \%)$ & $7(23 \%)$ & $8(24 \%)$ \\
\hline
\end{tabular}

IC/HH: infection control and hospital hygiene; IPSE: Improving Patient Safety in Europe; TRICE: Training needs assessment in Infection Control in Europe.

Considered in the Table are only 30 countries that answered both surveys (2006 and 2010) in 2010.

a More than one answer allowed.

the 51 courses, and a post-graduation certification (in those countries where there is no formal recognition of the IC/HH profession) for 13 courses. Thirteen courses did not report a formal recognition. Nineteen of the 51 courses were recognised by the Ministry of Health and/or a State Agency, 23 by universities, and four by professional chambers (this list includes eight courses that are recognised by two institutions). The duration of the training was 100 hours or less in eight courses; 101 to 200 hours in six courses, 201 to 300 hours in 15 courses, 300 hours or more in eight courses, and one or more years in 13 courses, one course did not report the duration. Remarkably, 28 training courses reported in 2010 that they had considered the European core curriculum developed by the IPSE project and three of these courses provided distance learning programmes (Figure 2).

The questionnaire also explored the professional status of IC/HH doctors and IC/HH nurses (Table 2) with respect to the presence of a job description, professional profile definition and official recognition of an $\mathrm{IC} / \mathrm{HH}$ degree. For IC/HH doctors, there was a slight increase in the percentage of countries reporting a job description from 11 of 31 in 2006 to 17 of 33 countries in $2010(p=0.20)$ and a significant increase in the percentage of countries that provided a professional profile definition from 18 of 31 countries in 2006 to 28 of 33 countries in $2010(p<0.05)$. However, the official recognition of the IC/HH degree did not increase between 2006 and 2010 and remained low at 16 of 33 countries for doctors and 19 of 33 for nurses (Table 2).

$\mathrm{IC} / \mathrm{HH}$ teams were defined within a national programme or regulation in 27 of 33 countries in 2010, compared with 21 of 31 countries in 2006. IC/HH doctors and IC/ $\mathrm{HH}$ nurses were confirmed as the most represented professionals in the IC/HH team (Table 3).
The initial specialisation (educational background) of IC/HH doctors was mostly microbiology, reported by 28 of 33 countries in 2010 , followed by infectious diseases in 17, epidemiology in 11, public health in nine and hygiene in seven of the 33 countries.

The most frequently reported initial specialisation for registered nurses before IC/HH specialisation for nurses was graduated/certified nurse in 28 of 33 countries, followed by intensive care nurse in six, operating theatre nurse in six, anaesthesiology nurse in three and other specialised nursing background in five countries. The level of seniority required to become an IC/ $\mathrm{HH}$ nurse was a minimum of three year of experience after qualification in 22 of the 33 countries, followed by being a senior head nurse in 10 countries.

\section{TABLE 3}

Healthcare professionals included in the infection control and hospital hygiene team in European countries, 2006 (IPSE, 21 countries) and 2010 (TRICE, 27 countries)

\begin{tabular}{|l|c|c|}
\hline \multirow{2}{*}{ Healthcare professionals } & \multicolumn{2}{|c|}{$\begin{array}{c}\text { Number (percentage) of countries } \\
\text { with characteristics for }\end{array}$} \\
\cline { 2 - 3 } & $2006(\mathrm{n}=21)$ & $2010(\mathrm{n}=27)$ \\
\hline IC/HH doctors & $21(100 \%)$ & $27(100 \%)$ \\
\hline IC/HH nurses & $20(95 \%)$ & $26(96 \%)$ \\
\hline Laboratory technicians & $4(19 \%)$ & $6(22 \%)$ \\
\hline Environmental technicians & $1(5 \%)$ & $3(9 \%)$ \\
\hline Data managers & $2(10 \%)$ & $1(3 \%)$ \\
\hline Administrative support & $10(48 \%)$ & $9(33 \%)$ \\
\hline Other & $0(0 \%)$ & $6(22 \%)$ \\
\hline
\end{tabular}

IC/HH: infection control and hospital hygiene; IPSE: Improving Patient Safety in Europe; TRICE: Training needs assessment in Infection Control in Europe.

a More than one answer allowed. 
The TRICE project also reassessed the tasks for which $\mathrm{IC} / \mathrm{HH}$ doctors are responsible or to which they contribute in their day-to-day practice. The most frequently reported tasks or areas of responsibility for $\mathrm{IC} / \mathrm{HH}$ doctors in 2010 were: outbreak identification and investigation, analysis and feedback of $\mathrm{IC} / \mathrm{HH}$ data and the development of an $\mathrm{IC} / \mathrm{HH}$ programme and work plan (Table 4).

The most frequently reported tasks or areas of responsibility for $\mathrm{IC} / \mathrm{HH}$ nurses in 2010 were: training of hospital employees in $\mathrm{IC} / \mathrm{HH}$ and the elaboration and implementation of $\mathrm{IC} / \mathrm{HH}$ procedures (Table 5 ). Although some significant differences in the individual tasks existed between 2006 and 2010, there was a strong correlation of the ranking of tasks by degree of responsibility (responsible or contributor) between the two surveys (Spearman's correlation coefficient 0.78 , $\mathrm{p}<0.001)$.

Besides the traditionally recognised tasks for $\mathrm{IC} / \mathrm{HH}$ doctors and nurses, it appeared that the discipline of
$\mathrm{IC} / \mathrm{HH}$ was expanding, with the inclusion of new components such as quality and risk management.

\section{Evaluation and finalisation of the core competencies}

The results of the evaluation of the IPSE core competencies were discussed at a meeting of the NRs in June 2010. During this meeting, some changes to the IPSE core competencies were agreed and it was decided to recommend only two categories because the intermediate-level category (see Methods) was used by the NRs less frequently than the two other categories when evaluating individual competencies and was considered too complex. Hence, two main levels of practice for $\mathrm{IC} / \mathrm{HH}$ training and professional development were agreed as follows:

Introductory level (junior specialist): newly appointed $\mathrm{IC} / \mathrm{HH}$ staff member with little or no previous experience;

Expert level (senior specialist): $\mathrm{IC} / \mathrm{HH}$ professionals who are confident and experienced, who use reasoning,

\section{TABLE 4}

Tasks for which infection control/hospital hygiene doctors played a role as responsible persons and or as contributors, European countries, 2006 (IPSE, 31 countries) and 2010 (TRICE, 33 countries)

\begin{tabular}{|c|c|c|c|}
\hline \multirow[t]{2}{*}{ Grade of responsibility } & \multirow[t]{2}{*}{ Task } & \multicolumn{2}{|c|}{$\begin{array}{l}\text { Number (percentage) of countries } \\
\text { reporting task }\end{array}$} \\
\hline & & $2006(n=31)$ & $2010(n=33)$ \\
\hline \multirow{12}{*}{ Responsible } & Identification and investigation of outbreaks & $21(68 \%)$ & $30(91 \%)$ \\
\hline & Analysis and feedback of IC/HH data & $21(68 \%)$ & $25(76 \%)$ \\
\hline & Elaboration of an IC/HH programme, workplan and projects & $19(61 \%)$ & $24(73 \%)$ \\
\hline & $\begin{array}{l}\text { Management (implementation, follow-up, evaluation) of an IC/HH } \\
\text { programme, workplan and projects }\end{array}$ & $20(65 \%)$ & $23(70 \%)$ \\
\hline & Design of a surveillance system & $15(48 \%)$ & $22(67 \%)$ \\
\hline & Elaboration of IC/HH procedures & $16(52 \%)$ & $22(67 \%)$ \\
\hline & Management (implementation, follow-up, evaluation) of HAl surveillance & $15(48 \%)$ & $21(64 \%)$ \\
\hline & Providing expertise in IC/HH policy & $16(52 \%)$ & $21(64 \%)$ \\
\hline & Training of hospital employees in IC/HH & $15(48 \%)$ & $20(61 \%)$ \\
\hline & Audits and performance evaluation of organisations and parts of them & $15(48 \%)$ & $19(58 \%)$ \\
\hline & Implementation of IC/HH procedures & $12(39 \%)$ & $17(52 \%)$ \\
\hline & Antibiotics policy & $14(45 \%)$ & $17(52 \%)$ \\
\hline \multirow{10}{*}{ Contributor } & Quality management & $21(68 \%)$ & $25(76 \%)$ \\
\hline & Elaboration of healthcare procedures & $18(58 \%)$ & $23(70 \%)$ \\
\hline & Risk management & $21(65 \%)$ & $23(70 \%)$ \\
\hline & Clinical management of infected or at-risk patients & $12(39 \%)$ & $22(67 \%)$ \\
\hline & Contributing to building renovation plans & NA & $21(64 \%)$ \\
\hline & Contribution to construction and design of healthcare buildings & NA & $20(61 \%)$ \\
\hline & Prescription of antibiotics & $12(39 \%)$ & $19(58 \%)$ \\
\hline & Employee health & $15(48 \%)$ & $19(58 \%)$ \\
\hline & Implementation of healthcare procedures & $17(55 \%)$ & $19(58 \%)$ \\
\hline & Selection of supplies or products used in the hospital & NA & $19(58 \%)$ \\
\hline
\end{tabular}

HAI: healthcare-associated infections; IC/HH: infection control and hospital hygiene; IPSE: Improving Patient Safety in Europe; NA: not available; TRICE: Training needs assessment in Infection Control in Europe.

Only the tasks reported by at least $50 \%$ of countries in 2010 are mentioned. 
Tasks for which infection control/hospital hygiene nurses played a role as responsible persons or as contributors, European countries, 2006 (IPSE, 31 countries) and 2010 (TRICE, 33 countries)

\begin{tabular}{|c|c|c|c|}
\hline \multirow[t]{2}{*}{ Grade of responsibility } & \multirow[t]{2}{*}{ Task } & \multicolumn{2}{|c|}{$\begin{array}{l}\text { Number (percentage) of countries } \\
\text { reporting task }\end{array}$} \\
\hline & & $2006(n=31)$ & $2010(n=33)$ \\
\hline \multirow{7}{*}{ Responsible } & Training of hospital employees in IC/HH & $18(58 \%)$ & $24(73 \%)$ \\
\hline & Elaboration of IC/HH procedures & $18(58 \%)$ & $23(70 \%)$ \\
\hline & Implementation of IC/HH procedures & $18(58 \%)$ & $21(64 \%)$ \\
\hline & Procedures for disinfection of medical devices & $13(42 \%)$ & $21(64 \%)$ \\
\hline & $\begin{array}{l}\text { Management (implementation, follow-up, evaluation) of an IC/HH } \\
\text { programme, workplan and projects }\end{array}$ & $14(45 \%)$ & $19(58 \%)$ \\
\hline & Audits and performance evaluation of organisations and parts of them & $14(45 \%)$ & $18(55 \%)$ \\
\hline & Identification and investigation of outbreaks & $13(42 \%)$ & $18(52 \%)$ \\
\hline \multirow{10}{*}{ Contributor } & Risk management & $22(71 \%)$ & $17(52 \%)$ \\
\hline & \begin{tabular}{|l|} 
Quality management \\
\end{tabular} & $22(71 \%)$ & $23(70 \%)$ \\
\hline & Design of a surveillance system & $18(58 \%)$ & $23(70 \%)$ \\
\hline & Employee health & $14(45 \%)$ & $21(64 \%)$ \\
\hline & \begin{tabular}{|l|} 
Elaboration of healthcare procedures \\
\end{tabular} & $20(65 \%)$ & $21(64 \%)$ \\
\hline & Research & $17(55 \%)$ & $20(61 \%)$ \\
\hline & Implementation of healthcare procedures & $17(55 \%)$ & $19(58 \%)$ \\
\hline & Clinical management of infected or at risk patients & $14(45 \%)$ & $18(55 \%)$ \\
\hline & Providing expertise in IC/HH policy & $14(45 \%)$ & $17(52 \%)$ \\
\hline & Work organisation in clinical units & $10(32 \%)$ & $17(52 \%)$ \\
\hline
\end{tabular}

IC/HH: infection control and hospital hygiene; IPSE: Improving Patient Safety in Europe; TRICE: Training needs assessment in Infection Control in Europe.

Only the tasks reported by at least $50 \%$ of countries in 2010 are mentioned.

critical thinking, reflection and analysis to inform their assessment and decision making and are able to develop and implement new solutions to problems.

The final agreed 'core competencies for infection control and hospital hygiene professionals in the European Union' are available from the ECDC website [13] and are organised in four areas (programme management, quality improvement, surveillance and investigation of $\mathrm{HAI}$, and IC/HH activities) and 16 domains, each with core competencies for a junior and a senior specialist. Table 6 summarises the structure of the document.

In this context it is necessary to stress that the specification was for $\mathrm{IC} / \mathrm{HH}$ specialists in acute care hospitals and that the core competencies were similar for $\mathrm{IC} / \mathrm{HH}$ nurses and $\mathrm{IC} / \mathrm{HH}$ doctors, including those competencies relating to antimicrobial stewardship because of the increasing numbers of prescribing nurses in European countries and their greater strategic involvement.

\section{Discussion}

The TRICE project has provided data for a comprehensive overview of the characteristics, training for professionals, tasks and related core competencies for European IC/HH professionals in 2010. It will also inform future trend analyses, as almost all countries have reported their current situation. The decision to use the questionnaire on core competencies that was used by the IPSE project in 2006, enabled us to evaluate the progress of European countries between 2006 and 2010. In particular, our results showed that IPSE initiatives and the European core curriculum developed by the project IPSE already had an impact on the creation of new national curricula for $\mathrm{IC} / \mathrm{HH}$ training, on the definition of professional profiles, in particular for $\mathrm{IC} / \mathrm{HH}$ doctors, and on the development or adaptation of the content of new or existing courses in European countries. Nevertheless, well-defined qualifications, standardised training pathways and agreed competencies for IC/HH professionals were still lacking in 2010. A critical point is that, in 2010 , almost half of the countries still did not have an official recognition of qualifications for an IC/HH doctor or an IC/HH nurse.

The professional backgrounds of IC/HH doctors and IC/ $\mathrm{HH}$ nurses in European countries were homogeneous, which should make the process of harmonisation of training programmes achievable. $\mathrm{IC} / \mathrm{HH}$ doctors were most commonly trained in microbiology, followed by infectious diseases, hygiene and public health. In 28 of 33 countries, IC/HH nurses had a minimum of three years of experience as a graduated/certified nurse. 
More than $80 \%$ of the respondents reported that a definition of the Infection Control Team existed in national programmes or regulations. The professionals most frequently included were doctors and nurses that were the focus of the survey. In future projects it would be useful to explore more in detail also the role of other professionals engaged in the infection control team.

The type of degree or learning to become an IC/HH specialist remained heterogeneous among European countries. This reinforces the need for common standards for the training of IC/HH professionals. In this context, our proposal for European core competencies for $\mathrm{IC} / \mathrm{HH}$ professionals in the European Union [13] is expected to promote the standardisation of the competencies of IC/ $\mathrm{HH}$ professionals in Europe and the design and implementation of training courses according to different national contexts and to facilitate the mutual recognition of competencies across Europe. It further serves as an opportunity for $\mathrm{IC} / \mathrm{HH}$ professionals to review their own performance and plan their professional development and for healthcare institutions and organisations to evaluate their needs in terms of professional human resources and to evaluate the performance of the existing IC/HH professionals.

European core competencies are useful for countries without a national curriculum or programme to promote new training initiatives for $\mathrm{IC} / \mathrm{HH}$ professionals according to European standards. For other countries, European core competencies represent an opportunity to identify gaps in their curricula and to organise $\mathrm{IC} / \mathrm{HH}$ according to the different levels of expertise. These European core competencies will thus act as a point of reference for the development of $\mathrm{IC} / \mathrm{HH}$ training initiatives and harmonisation of these courses and qualifications.

Professional competency grows in a continuum, where the speed and the completeness depend on several parameters. Under certain circumstances, these competencies will have to be developed very quickly. This will depend on many variables such as the expectation that $\mathrm{IC} / \mathrm{HH}$ doctors or nurses will chair an $\mathrm{IC} / \mathrm{HH}$ committee at an agreed time after appointment, on how long there have been $\mathrm{IC} / \mathrm{HH}$ doctors or nurses in a country, on whether adequate resources are available (e.g. administrative support), on the presence and need to interact with audit/patient safety departments, and on IC/HH team members' aptitudes, preferences and previous experiences. For example, some new $\mathrm{IC} / \mathrm{HH}$ professionals may have acquired considerable management experience and transferable skills from previous positions in other specialties before embarking upon their IC/HH career.

The proposed core competencies for IC/HH professionals in the European Union were developed in 2010. Since this date, the North American Certification Board

\section{TABLE 6}

Core competencies for infection control and hospital hygiene professionals in the European Union, by area and domain, 2010

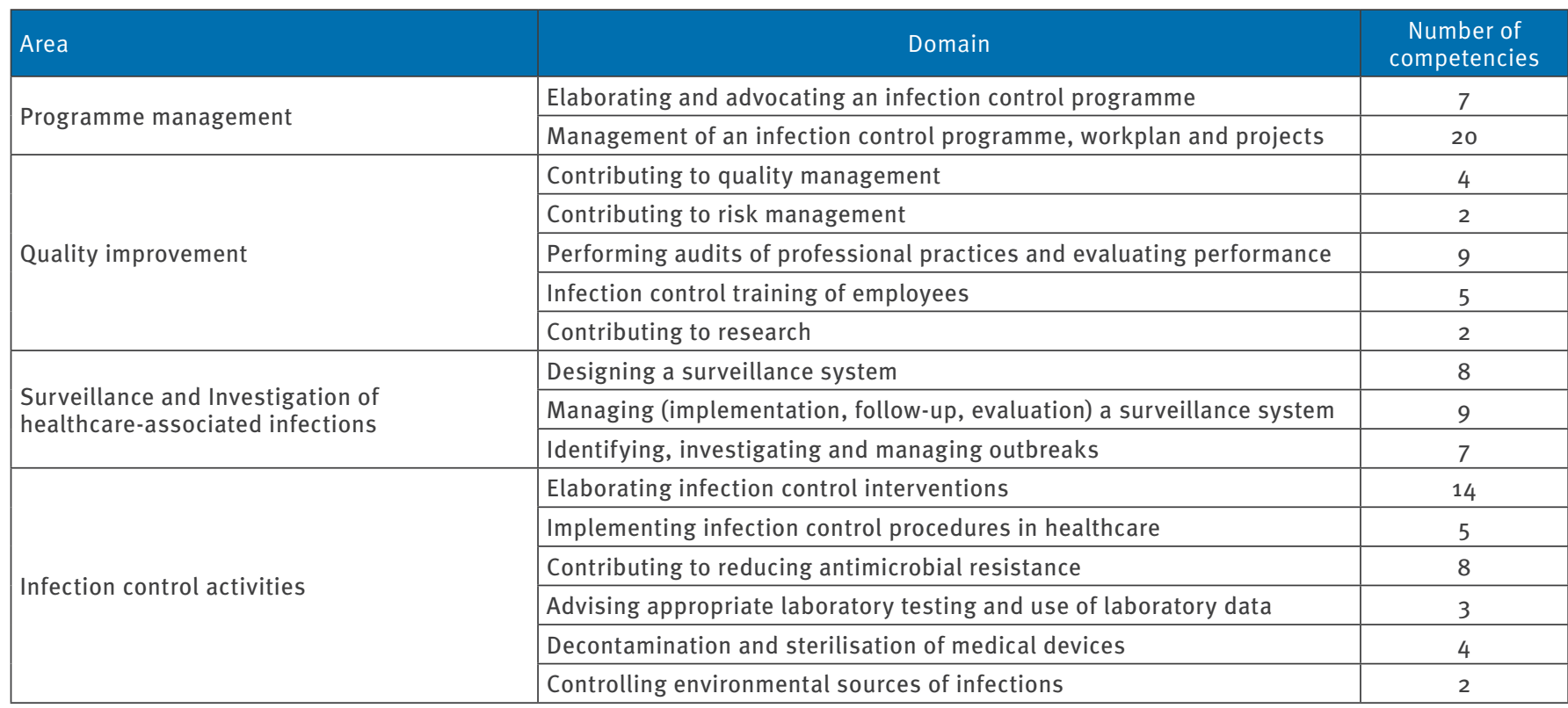

IC/HH: infection control and hospital hygiene; IPSE: Improving Patient Safety in Europe; TRICE: Training needs assessment in Infection Control in Europe.

Only the tasks reported by at least $50 \%$ of countries in 2010 are mentioned. 
of Infection Control and Epidemiology (CBIC) has published a proposal for a conceptual model including four specific domains that represent the areas for future development of competencies: leadership, infection prevention and control, technology and performance improvement and implementation science [15]. This model does not conflict with the European approach, although it proposes an intermediate level (proficiency) between the expert and the novice. Such an intermediate level was considered by the NRs but was rejected as they expected that it may add confusion to the already heterogeneous situation in Europe. The TRICE two-level approach was considered more effective to promote standardisation of $\mathrm{IC} / \mathrm{HH}$ training, and it takes into account the important diversity of duration and content of the existing $\mathrm{IC} / \mathrm{HH}$ training courses in Europe. Furthermore, all participants to the TRICE agreed that a minimum of competencies for junior/ introductory level was useful for both organisations and professionals and acting as a platform for personal and professional development.

The NRs also recommended that the proposed core competencies for $\mathrm{IC} / \mathrm{HH}$ professionals in the European Union [13] should be seen as stages of a journey with a distinction between the two main categories (junior specialist/introductory level and senior specialist/ expert level). They should be useful for the production of tools aimed at helping the development of IC/ $\mathrm{HH}$ training courses. The introductory level should be considered appropriate for those involved in all technical/common tasks and responsibilities, whereas the expert level should apply to professionals with experience of political challenges or with new, complex, unusual or unexpected situations. The proposed core competencies should address the design of training courses developed preferably according to the Bologna process for standardisation of credits and recognition and to the standards proposed by the European Association for Quality Assurance in Higher Education [16], and they should be owned by those involved as trainers in these courses.

\section{Conclusion}

Based on the findings of the TRICE project, we consider that Europe is moving toward acknowledgement and a higher priority for HAl prevention and control. There is nevertheless room for improvement, especially in the recognition of the $\mathrm{IC} / \mathrm{HH}$ degree for $\mathrm{IC} / \mathrm{HH}$ professionals and in the standardisation and mutual recognition in Europe of the $\mathrm{IC} / \mathrm{HH}$ training initiatives.

The future impact of the core competencies for $\mathrm{IC} / \mathrm{HH}$ professionals in the European Union [13] will depend on (i) the existence of validated IC/HH training courses designed and delivered to enable the acquisition of these competencies, (ii) the widespread recognition that $\mathrm{IC} / \mathrm{HH}$ doctors and $\mathrm{IC} / \mathrm{HH}$ nurses need these competencies to ensure that a hospital IC/HH programme meets its goals and agreed deliverables, (iii) the existence of a sustained strategy ensuring that the core competencies are updated and reviewed at European level and owned and adopted by those running the training courses and (iv) the sustained coordination of, and support for a network for $\mathrm{IC} / \mathrm{HH}$ training in Europe that will ensure the long-term commitment of institutions to the programmes.

Finally, while training of $\mathrm{IC} / \mathrm{HH}$ professionals should become a priority for European countries, more emphasis should also be given to basic training in $\mathrm{IC} / \mathrm{HH}$ in nursing schools and in medical universities. Ensuring that all healthcare personnel has received such basic training before starting their professional activity would certainly contribute to further improvement in the quality of healthcare throughout Europe.

\section{Acknowledgements}

The authors wish to thank the members of the pedagogic committee of Work Package 1 of the IPSE project (European Commission, DG SANCO, Project no. 790903, Grant Agreement no. 20044216) who developed the first version of the "Core competencies for infection control and hospital hygiene professionals in the European Union". Project coordination: Jacques Fabry, Josette Najjar-Pellet (Claude Bernard University Lyon 1, France); ESCMID representatives: Benedetta Allegranzi (WHO, Geneva), Jette Holt (Statens Serum Institute, Copenhagen, Denmark), Christian Ruef (Division of Infectious Diseases and Hospital Epidemiology, Hirslanden Hospital and Medical Center, Zurich, Switzerland), Nina Kristine Sorknes (Norwegian Institute of Public Health, Oslo, Norway) and Andreas Voss (Radboud University, Nijmegen, The Netherlands); Barry Cookson (Division of Infection and Immunity, University College London, United Kingdom).

Funding: The 'Training in Infection Control in Europe' (TRICE) project was funded by ECDC through a specific service contract (ECD.1840) with the University of Udine, Italy.

\section{Conflict of interest}

None declared.

\section{Authors' contributions}

Silvio Brusaferro coordinated the project. Silvio Brusaferro, Barry David Cookson, Francesco Coiz, Elisa Fabbro, Carl Suetens, Carmen Varela Santos, Smilja Kalenic, Rose Gallagher, Tracey Cooper, Jacques Fabry, Philippe Hartemann, Kerstin Mannerquist, Walter Popp, Gaetano Privitera, Christian Ruef, Pierluigi Viale designed the study, designed the questionnaire, contributed to the analyses of the results, drafted and commented on revisions to the manuscript and gave the final approval of this version. Silvio Brusaferro and Francesco Coiz conducted the statistical analysis. The National representatives of the project completed the national questionnaire, revised the manuscript and gave the final approval of this version. National representatives of the Training in Infection Control in Europe (TRICE) project

AUSTRIA Blacky A Department of Hospital Hygiene, Medical University of Vienna

BELGIUM Simon A University of Leuven

BULGARIA Vatcheva-Dobrevska $R$ National Centre of

Infectious and Parasitic Diseases, Sofia

CROATIA Budimir A University Hospital Center, Zagreb \&

School of Medicine, University of Zagreb,

CYPRUS Stavroulla S Ministry of Health, Cyprus 
CZECH REPUBLIC Šturma J National Institute of Public Health, Prague

DENMARK Holt J National Unit of Infection Control, Statens Serum Institute, Denmark

ESTONIA Lemetsar A Health Board,Tallinn

FINLAND Lyytikäinen 0 National Institute for Health and Service, Helsinki

FRANCE Astagneau P Coordinating centre for nosocomial infection control (CCLIN), Department of Public Health, University School of Medicine, Paris

GERMANY Mielke M Robert Koch-Institut, Berlin

GREECE Ftika L Hellenic Centre for Disease Control and Prevention (HCDCP), Athens

HUNGARY Hajdú Á Hospital Epidemiology Department, National Center for Epidemiology, Budapest

IRELAND Donlon S Health Protection Surveillance Centre, Dublin

ITALY Moro M L Regional Health Agency, Bologna

LATVIA Nikiforova R Infectology Centre of Latvia

LITHUANIA Gailiene G Institute of Hygiene, Vilnius

LUXEMBOURG Heisbourg E Health Directorate, Ministry of Health, Luxembourg

MALTA Borg M Infection Control Unit, Mater Dei Hospital, Msida

NETHERLANDS Ummels L Radboud University Medical Centre, Nijmegen

NORWAY Sorknes N Norwegian Institute of Public Health, Oslo

POLAND Stefanof P National Institute of Public Health (NIZPPZH), Warsaw

PORTUGAL Costa C Directorate-General of Health, Lisbon ROMANIA Pitigoi D National Institute of Infectious Diseases Prof Dr MateiBals, Bucharest

SLOVAKIA Kristufková Z Slovak Medical University, Faculty of Public Health, Bratislava

SLOVENIA Kolman J National Institute of Public Health, Ljubljana

SPAIN Pareja-Bezares A Epidemiology and Infection Control Unit. Hospital Son Llàtzer, Palma de Mallorca

SWEDEN Mannerquist K Swedish Institute for Infectious Disease Control, Stockholm

TURKEY CetinkayaSardan Y Refik Saydam National Public Health Agency, Ankara

UNITED KINGDOM (UK)* Sheridan E Health Protection Agency (HPA), London

UK-ENGLAND Sheridan E Health Protection Agency (HPA), London

UK-NORTHERN IRELAND Mills A Northern Ireland Government, Belfast

UK-SCOTLAND Faser C Scottish Government, Edinburgh

UK-WALES Gauci T Wales Government, Cardiff

\section{References}

1. Council of the European Union. Council recommendation of 9 June on patient safety, including the prevention and control of healthcare-associated infections (2009/C151/01). Official Journal of the European Union. 3 Jul 2009. Available from: http://ec.europa.eu/health/patient_safety/docs/ council_2009_en.pdf

2. Cookson BD, Jenner EA, Roberts C, Drasar B, Ridgway G. Diploma in Hospital Infection Control: a progress report. J Hosp Infect. 2001;48(2):146-51. http://dx.doi.org/10.1053/ jhin.2001.0954 PMID:11428883

3. Goldrick BA. The practice of infection control and applied epidemiology: a historical perspective. Am J Infect Control. 2005;33(9):493-500. http://dx.doi.org/10.1016/j. ajic.2005.04.250 PMID:16260324

4. Bijl D, Voss A. Infection control in the Netherlands. J Hosp Infect. 2001;47(3):169-72. http://dx.doi.org/10.1053/ jhin.2000.0885 PMID:11247675

5. Melo-Cristino J, Marques-Lito L, Pina E. The control of hospital infection in Portugal. J Hosp Infect. 2002;51(2):85-8. http:// dx.doi.org/10.1053/jhin.2002.1218 PMID:12090794

6. Brusaferro S, Quattrin R, Barbone F, D’Alessandro D, Finzi GF, Cimoroni $M$, et al. Factors influencing hospital infection control policies in Italian hospitals. J Hosp Infect. 2003;53(4):268-73. http://dx.doi.org/10.1053/jhin.2002.1376 PMID:12660123

7. Daschner FD, Cauda R, Grundmann H, Voss A, Widmer A. Hospital infection control in Europe: evaluation of present practice and future goals. Clin Microbiol Infect. 2004;10(3):263-6. http://dx.doi.org/10.1111/j.1198743X.2004.00819.x PMID:15008951

8. IPSE - Improving Patient Safety in Europe. The IPSE report 2005-2008. Lyon: Université Claude Bernard Lyon1; Nov 2009. Available from: http://www.ecdc.europa.eu/en/ activities/surveillance/HAI/Documents/0811_IPSE_Technical Implementation_Report.pdf

9. Directive 2011/24/EU of the European Parliament and of the Council of 9 March on the application of patients' rights in cross-border healthcare. Official Journal of the European Union. Luxembourg: Publications Office of the European Union; 4.4.2011:L 88/46. Available from: http://eur-lex.europa.eu/ LexUriServ/LexUriServ.do?uri=0J:L:2011:088:0045:0065:EN:P DF

10. Farrington M, Pascoe G. Risk management and infection control--time to get our priorities right in the United Kingdom. J Hosp Infect. 2001;47(1):19-24. http://dx.doi.org/10.1053/ jhin.2000.0829 PMID:11281116

11. World Health Organization (WHO). WHO Patient Safety Curriculum Guide for Medical Schools. Geneva: WHO; 2009. Available from: http://www.who.int/patientsafety/activities/ technical/who_ps_curriculum.pdf

12. World Health Organization. WHO patient safety curriculum guide: multi-professional edition. World Health Organization, Geneva Switzerland 2011.

13. European Centre for Disease Prevention and Control (ECDC). Core competencies for infection control and hospital hygiene professionals in the European Union. Stockholm: ECDC; 2013 Available from: http://www.ecdc.europa.eu/en/publications/ publications/infection-control-core-competencies.pdf

14. European Commission. The European Qualifications Framework for Lifelong Learning (EQF). Luxembourg: Office for Official Publications of the European Communities, 2008. ISBN 978-9279-08474-4. http://dx.doi.org/10.2766/14352. Available from: http://www.ond.vlaanderen.be/hogeronderwijs/bologna/ news/EQF_EN.pdf

15. Murphy DM, Hanchett M, Olmsted RN, Farber MR, Lee TB, Haas $J P$, et al. Competency in infection prevention: a conceptual approach to guide current and future practice. Am I Infect Control. 2012;40(4):296-303. http://dx.doi.org/10.1016/j. ajic.2012.03.002 PMID:22541852

16. European Association for Quality Assurance in Higher Education (ENQA). Standards and Guidelines for Quality Assurance in the European Higher Education Area. Helsinki: ENQA; 2009. ISBN 952-5539-05-9. Available from: http://www. enqa.eu/wp-content/uploads/2013/06/ESG 3edition-2.pdf 